\title{
CLEAN BLOOD, RELIGION AND MORAL TRIAGE IN TUBERCULOSIS \\ VACCINE TRIALS
}

Justin Dixon and Michèle Tameris

\begin{abstract}
During ethnographic research at a tuberculosis vaccine trial site in South Africa, trial participants often evoked the idiom of "clean blood." In this article, we illustrate how the trials enacted a form of moral triage in which "objective" bioscientific knowledge and moral subjectivity were coproduced. Participation created possibilities to demonstrate healthiness, respectability, and godliness in a context where positive self-imaginings were hard won, but could equally lead to dejection and shame. We suggest that struggles to be recognized as virtuous are often overlooked in anthropological critiques of clinical trials and bioethics, but are important for understanding how trials meld with local moral worlds.
\end{abstract}

Key words: South Africa, bioethics, clinical trials, morality, religion, tuberculosis Running title: Clean Blood, Religion and Moral Triage

Media teaser: What might clinical trial participation mean in impoverished settings beyond material benefit? What else can blood reveal besides biological states? 


\section{Bionotes}

JUSTIN DIXON is a Research Fellow in Medical Anthropology at the London School of Hygiene and Tropical Medicine. Justin is also an Honorary Fellow in the anthropology at Durham University, which is where his $\mathrm{PhD}$ graduate studies were conducted, including the research for this article. He can be contacted at: LSHTM, 15-17 Tavistock Place, London WC1H9SH. Email: Justin.Dixon@1shtm.ac.uk

MICHÈLE TAMERIS is a clinical researcher at the South African Tuberculosis Vaccines Initiative (SATVI), Department University of Cape Town and since 2005 has been involved in 21 clinical trials of 9 candidate TB vaccines. She is also the recipient of two Wellcome Trust International Engagement awards. She can be contacted at: South African Tuberculosis Vaccine Initiative, Institute of Infectious Diseases and Molecular Medicine, University of Cape Town, Anzio Road, Observatory, Cape Town, South Africa. Email: Michele.Tameris@uct.ac.za 
One morning in 2013, a young man called Leighton ${ }^{1}$ walked into the study clinic of the South African Tuberculosis Vaccines Initiative (SATVI), a research institute that has been conducting TB vaccine trials in the Western Cape since 2001. Leighton had come to be screened for a tuberculosis (TB) vaccine trial. Susanna, the research nurse with whom he interacted, noticed that he was drunk, which precluded the possibility of her proceeding. Trying not to sound judgmental and not wanting to deter him from returning, she said to him, "you must try if you come here again, not to do this, because otherwise our blood results and things, they will be whack." Leighton did come again, a year later in 2014. Susanna explained, with no small measure of pride, that he had "passed" screening with no difficulties. Seeing him looking very different, she had remarked to him, "oh, you look smart today!" Susanna related how she sat with him during the routine procedures:

I said to him, he looks like my brother, actually. And he said "is it?" and then I said I loved him so much...but he died of TB. He was my best brother. But his lifestyle, his lifestyle. Because it was so painful for our whole family, but I know he [Leighton] can do better. I always tell them they can do better. Do you know who you are? And you're not supposed to do things like that. You can try, you can try. And the next time he came in, he said "I will do my best."

Susanna was the wife of a pastor, and when she was not working at SATVI she helped run their well-attended church. This had a significant effect on how she engaged with participants. When the first author (JD) interviewed Leighton, he said that he had initially wanted to take part to check if he had TB. However, upon being enrolled into the trial, something profound happened:

L: I was doing things that were affecting my health: smoking and drinking. But when I started to attend here, it's when I quit those things to become a normal person because those things go into my blood. 
J: So what was it about taking part that made you decide to stop smoking and drinking?

L: I stopped everything and I became a reborn Christian. So it also helped me because I want to be in this study also to stop these things. Because if I keep on doing that, I'm with God. Because they told me when they test my blood and all those things. I said, no, I cannot jeopardize my health and jeopardize God, so that means I need to lead my life better.

The interactions between Susanna and Leighton reveal an intertwining of social phenomena during the routine practices of a trial, and include $\mathrm{TB}$, blood, lifestyle, religion, and morality. Although unique in certain respects, Leighton's experiences resonate with the way others made meaning of SATVI's trials and their role in them as participants.

This article is about the entanglement of SATVI's TB vaccine trials in the worldbuilding efforts of people situated on the peripheries of social and economic life, and their attempts to frame themselves as moral, valuable, and respectable people. Focusing upon the popular idiom of "clean blood" which recurred throughout the trials (alluded to in the vignette), we show that by drawing and testing blood, moral subjectivity was made visible and intervened in the same moment that trial protocols sought to produce "objective," generalizable knowledge (Carsten 2013a; Stadler et al. 2016). We argue that the conduct of trials in this setting enacted a form of moral triage, compelling or affirming "good" lifestyles in ways beyond the requirements of trial protocols. For some people, trial participation could become a powerful and, in Leighton's case, evangelical - "strategy of self-improvement" (Jensen 2008:181). Participation thereby provided a platform from which to struggle back against enduring patterns of domination, exclusion and racial stereotyping in the Cape (Jensen 2008; Ross 2010). Equally, for others who "failed" triage, the trials could be a source of further dejection and shame. 
By focusing on what blood can reveal about moral subjectivity, our account departs from studies of medical research in Africa which have depicted blood as featuring in unequal systems of material exchange and in structures of postcolonial extraction (Geissler 2005; Fairhead, Leach, and Small 2006; Geissler et al. 2008). By the same token, our analysis offers a counterpoint to an established anthropological critique of bioethics, which has highlighted the naivety of principles such as "autonomy" and "volunteerism" when applied in low-income settings where neoliberal reforms have severely limited people's access to healthcare (e.g. Geissler 2013; Kingori 2013, 2015). Without losing sight of the material inequities informing trial participation, we aim to show that trials can generate possibilities to demonstrate healthiness, respectability, and even "godliness" in environments where positive selfimaginings must be hard fought for. We suggest that struggles to be recognized as virtuous and respectable are easily overlooked given the emphasis on material "benefits", but are nonetheless important for understanding how clinical trials meld with local moral worlds.

The fieldwork upon which this article is based took place between August 2014 and August 2015 at SATVI's trial site, located on the premises of a TB hospital in the town of Worcester in Cape Winelands District of the Western Cape. The site has a main office building, clinic areas, a laboratory, and a pharmacy. The project from which the data for this article are drawn aimed to explore the effects of SATVI's trials on health seeking and delivery in the Cape Winelands since 2001. We followed four trials that were ongoing at the time of fieldwork: two involving adults, one involving adolescents and one involving HIV-exposed infants. Participant observation and interviews were conducted by the first author with 40 research staff (doctors, nurses and fieldworkers), 98 trial participants (or the mothers of infants) (65 adults, 33 adolescents), and 20 doctors and nurses working in three public clinics with which SATVI works. Participant observation was conducted firstly during SATVI's daily clinics, where participants attended screening, vaccination and follow-up visits, and secondly, in the public 
clinic TB departments to provide insights into routine healthcare delivery. Interviews with participants took place during SATVI site visits.

The article is structured empirically around the interactions between Susanna and Leighton. This case offers a rich example of how the idiom of "clean blood" manifested in interpersonal relations, how it was shaped by multiple roles and subject positions, and the effects that it could have on participants' lives beyond the trials. It encapsulates fragments of meaning-making that appeared across a range of perspectives, allowing us to connect and interpret them in ways that are illuminating and informative. As well as analyzing particularities of this case, we use it as a guiding frame and a point of reference from which to introduce and layer a range of perspectives on trial participation and life in the Western Cape. One limitation of this example, as with our research design more generally, is that it privileges the viewpoints of participants who were included in (or not yet excluded from) the trials, leading us to present more data relating to positive experiences of moral triage than negative ones. In the penultimate section, we relate hints that we received towards the dejection and shame that could accompany exclusion from the trials. Yet, our research would have benefitted from the inclusion of the excluded, an omission of which we are cognisant when relating our findings.

\section{MAKING RELATIONS IN MEDICAL RESEARCH: THE PLACE OF BLOOD}

Studies of the political economy of clinical trials have shown how neoliberal reforms have systematically made disadvantaged people available as objects of experimentation, both in the context of the pharmaceutical industry (Sunder Rajan 2005, 2017; Abadie 2008; Fisher 2009; Petryna 2009) and the biopolitics of humanitarian medicine (Nguyen 2005, 2010, 2015; Wendland 2008; Rottenburg 2009). Clinical trials are tightly regulated and must adhere to ethical guidelines (e.g. Good Clinical Practice [GCP]) for the protection of human subjects. Yet, because of the narrow focus on individual "autonomy" and "choice" and the 
bureaucratization of ethical review, structural inequalities tend to fall beyond the purview of ethical scrutiny (Wendland 2008; Petryna 2009; Geissler 2013; Simpson et al. 2015). Indeed, as Petryna (2009) argues, GCP facilitates the travel of clinical trials into countries with weak regulatory structures and obliging bodies.

Whilst these studies situate trials in their broader political-economic context, "global" scientific norms must be made to work in particular socio-economic and cultural settings (Sariola and Simpson 2011). Ethnographic research at trial sites in Africa has explored what it means to conduct ethical research in Africa's neoliberal healthcare landscapes, where trials are sometimes understood in terms of the exchange of blood for medicine (Geissler 2005; Fairhead, Leach, and Small 2006; Geissler et al. 2008; see also White 2000) and where the success of trials is dependent partially on the ability of local fieldworkers to couch trial relationships within familiar idioms of kinship and community (Geissler et al. 2008; Molyneux et al. 2013; Geissler 2013; Kingori 2013, 2015; Kamuya et al. 2014). These works provide valuable insights into medical research in resource-poor settings, showing how the relational ties that undergird the production of "objective" bioscientific knowledge confound assumptions about "autonomy" and "volunteerism." Yet, by foregrounding material difference, they have a tendency to reduce the significance of clinical trials in participants' lives to accessing scarce material "benefits." A number of recent studies have shown how trial protocols take on moral significance and, while still grounded in relational ties, they reveal other critical dimensions of the trial encounter. Exploring an HIV-prevention trial in Johannesburg, Stadler and colleagues (2016) showed that for participating women, the trial became a "symbol of hope," offering a rare opportunity to gain "recognition and respect." Moreover, the requirements of trial protocol shaped what it meant to be "healthy and virtuous" (2016:508). Brives $(2013,2016)$ has similarly shown in Burkino Faso that for women enrolled in a mother-to-child HIV transmission trial, the protocol shaped what it meant to be a "good mother" (2013:411). To these categories, we 
will add: what it means to be "with God" - as Leighton found as he "converted" to SATVI's trial.

This growing attention to the coproduction of knowledge and moral subjectivity intersects with work on morality in global health, which has drawn attention to how biomedical categories and interventions shape and "responsibilize" novel subjectivities (e.g. Robins 2006; Nguyen 2010; Black 2015). Our notion of “moral triage” builds upon Nguyen's (2010) work on triage in West Africa. Nguyen showed that access to antiretrovirals (ARVs) was contingent upon joining self-help groups and employing Western-derived confessional technologies, with ARVs allocated on the basis of who made the best advocates. We share Nguyen's contention that designations of "worthy" and "unworthy" are produced through engagements wth biomedicine. However, unlike Nguyen, we avoid locating triage within a rupture in the biopolitical order where state healthcare is supplanted by new fragmented sovereignties. The moral order described here is not a product of neoliberal global health, but emergent within everyday struggles back against the inscriptions of a state still heavy in its capacity to dominate and control. To capture how SATVI's trials gained moral force, we pay close attention to the "fluid, ongoing social constitution of morality through the embodied performance of linguistic practices" (Black 2015:248; see also Zigon 2008) - or more accurately in this context, the embodied performance of scientific practices and routines. By analysing how science was performed in this setting, we theorize participation not as an "empty choice" (Kingori 2015) to access scarce resources, but rather as one imbued with moral valence through people's attempts to recast themselves as virtuous and respectable.

In keeping with this argument, we reframe the significance of blood in clincial trials, focusing not on its exchange value, but rather on what it can reveal. In the introduction to a collection of papers exploring the symbolic dimensions of blood, Carsten (2013a:S13) observes that a recurring theme across time and space is the notion that blood is "the stuff of truth ... 
morally, personally, politically and medically." Carsten (2013b:S130) illustrates her assertion by examining a politically charged incident in Malaysia, where a blood sample taken from a member of the opposition "was claimed by some as having the capacity to 'reveal the truth' about his character." Stadler and colleagues (2016) found Carsten's insights useful for explaining the significance of blood draws in clinical trials. Noting that the women often lied about taking the experimental product, they show that these women feared that blood had the ability not only to expose their non-adherence, but also to signal sexual promiscuity. We also draw upon, and further expand, Carsten's observations. But whereas Stadler and colleagues' (2016) primary concern was with explaining the social context and significance of women's "lies," we focus on how the truths told by blood connected internal states with public good, generating novel possibilities to demonstrate moral worth. Moreover, whilst Stadler and colleagues focus upon the experiences of women, we describe the experiences of both women and men, especially young men, whose "immoral" and "irresponsible" behavior have deep roots in the colonial history of the Western Cape, to which we now turn.

\section{SATVI IN POST-APARTHEID CONTEXT}

Worcester, the largest town in the Western Cape's interior, remains divided along racial lines despite the freedom of movement brought about by the end of apartheid in 1994. The town is divided by a long road called Durban Street, which separated those labelled "white" from "nonwhite" under apartheid. North of the road live the town's more affluent residents, including the majority of town's white, primarily Afrikaans-speaking population (14\%). South of the road, in the town's less affluent suburbs, live the majority of residents, the largest proportion of whom are "Cape Coloured," Afrikaans-speaking people (60\%). Finally, on the town's outskirts lies the majority "black African" township of Zwelethemba (25\%), most of whom speak isiXhosa. The vast majority of SATVI's participants are enrolled from the latter two areas because of the 
high incidence of TB (1.5/100). South Africa's TB burden is closely linked to HIV: $57 \%$ of TB patients are co-infected with HIV, and TB is the leading cause of mortality among HIV-positive individuals (WHO 2016). Yet despite having comparatively low rates of HIV, the Western Cape's TB burden is amongst the most severe. Compion (2008:28) observes that the Western Cape's TB burden is a "unique epidemic within an epidemic," driven by "rapid urbanization and poor housing conditions, poor nutrition, overcrowding, unemployment, a short supply of nursing staff and clinics, as well as numerous social issues like alcoholism, drug abuse and domestic instability." Worcester is no different. In addition to widespread poverty, Worcester has considerable gang-related violence, high levels of alcoholism and substance abuse, and overburdened public clinics.

SATVI works closely with three public clinics. One is located in the center of Worcester, another in Zwelethemba, and the third $10 \mathrm{~km}$ outside of Worcester. These were busy, often stressful environments, and many of the clinic staff expressed concern about residents' apparent lack of concern for health and well-being. At the time of fieldwork, there were 741 active TB cases at the clinic in Worcester, 393 at the clinic in Zwelethemba and 389 at the third. Moreover, drug-resistant cases of TB were on the rise (O'Donnell et al. 2013; WHO 2016), due inter alia to high rates of "defaulting," that is, TB patients who prematurely stopped treatment. The appropriateness of the term "defaulter" has been hotly contested, and an established body of anthropological research has highlighted how TB discourse deflects attention away from structural determinants of the disease and (non-) adherence, and onto the behavior of the sick (Farmer 1998, 2000; Harper 2006; Compion 2008; Abney 2011). Nonetheless, the term holds currency in South African clinics and, when tensions ran high, justified scolding and disciplining (Jewkes, Abrahams, and Mvo 1998; Walker and Gilson 2004). One nurse said:

You can't be nice to them. If you give them the pinky [little finger] then they 
will take the whole hand. Some of the sisters try to be nice to them but it is only me that will give them skel [a scolding]. Nobody likes me here. Only God loves me [she points upwards to the heavens]!

While only a minority of patients demonstrated an apparent unwillingness to "take responsibility" for their health, this image was widely generalized. The facility manager of one clinic remarked: "The kind of community that we are serving, they are very ... it seems as if they don't care. They really don't care." Such attitudes towards residents were reinforced by Worcester's high rates of alcoholism, drug abuse, smoking, and gang violence - challenges which, while embedded in the enduring legacy of apartheid, were easily read as individual and collective moral failing.

Discourses of patient irresponsibility are common in African public health and medical research programs, with men in particular viewed as irresponsible and prone to non-adherence (e.g. Montgomery 2012; Stadler et al. 2016). In the Cape, perceptions of irresponsible lowincome communities are closely entwined in the historical construction of the Cape Coloured population. On the basis of lighter skin than Black Africans, those labelled "Coloured" were viewed with ambivalence by the colonial and apartheid regimes, neither the antithesis of white civilization nor included within it. Under apartheid, they were situated hierarchically and spatially in a "buffer zone" (Jensen 2008:2) between Whites and Black Africans, with access to the urban centers that were prohibited to black people. Yet as Jensen argues, from when Cape Coloureds were first recognized as a discrete group in the colonial era, various commissions into their status and well-being framed them very negatively. With no regard for the poverty in which they were forced to live, they were portrayed as "lacking in commitment and moral fiber, and a general image of the colored problem family in need of state attention was evoked" (2008:25). A key stereotype that emerged was the skollie. In Afrikaans, skollie literally means "scavenger," but in Cape Town it came to mean "thug" or "hooligan," referring to someone 
who is poor, male and Coloured, who refuses to work, is a criminal, drinks, and terrorizes working people (2008:2). Jensen argues that the skollie is closely entwined in the construction and governance of the Coloured population and continues to undermine positive Coloured identities in post-apartheid South Africa:

Colouredness is split between individuals' everyday sense of being themselves as persons who live normal and moral lives on the one hand, and on the other the colouredness, sustained by the full gamut of stereotypical framing and definition. These two forms of consciousness exist simultaneously but not on an equal level. The form of consciousness based in governmental framing and definition might be repudiated, but it will never be entirely expunged (2008:8).

Against this backdrop, Jensen and other anthropologists working in Afrikaans-majority townships in Cape Town have shown how people attempt to struggle against the inscriptions of the state to emerge as moral and respectable people, through avenues such as religion, community politics, homemaking, sport - even gang life (Salo 2003; Jensen 2008; Ross 2010). In this article, we show how these issues manifest in the health sector. In particular, we suggest that SATVI's trials feature alongside - and often overlap with - other spaces, strategies and institutions with which people confront and seek to overcome governmental framing and definition.

\section{ENTERING THE TRIAL}

The majority of SATVI's participants were recruited from the low-income suburbs of Worcester with which the public clinics struggled. Of the 65 adults interviewed, $40 \%$ were unemployed, and the remainder were typically employed in low-earning, often unstable jobs such as domestic workers, farm workers, factory workers, shop assistants and home-based 
carers. Research staff generally felt that the main reason people chose to take part in the trials was for the R150 “reimbursements"2 provided for study visits (Geissler 2011). Staff considered this to be a significant sum of money, and given the high rates of alcoholism and drug abuse, they felt that the money often went to feeding such habits. Certainly, the quiet assumption was that the money was greasing the wheels of the recruitment bandwagon.

Talking to participants themselves revealed a different picture. Of the 98 participants interviewed, $40(41 \%)$ cited altruistic reasons for taking part; $59(60 \%)$ cited personal health reasons; and $16(16 \%)$ cited money. ${ }^{3}$ Notably, many participants were highly conscious to distance themselves from the money in order to position the moral desirability of their intentions (cf. Kamuya et al. 2014; Kingori 2015). Sometimes with their hands gesturing towards their chests, their narratives of participation began with statements of the following form: "In my life it is not money that is important, it is my health" (40, Female, Xhosa); "For me it isn't about the money. What is it to give to someone and you can save a life?" (18, Male, Afrikaans). Such statements suggest that participants were well-aware of the prevailing stereotypes and felt compelled to consciously repudiate them before explaining what participation meant to them.

Although SATVI did not have the capacity to treat any diseases picked up during vaccine trials (rather, participants were referred to their local public clinic), many people valued the regular health checks, examinations, and blood screenings that were performed throughout the trials (Barsdorf et al. 2010; Abrams, Siegfried, and Geldenhuys 2011; Stadler et al. 2016). Moreover, almost all participants knew someone who had suffered from TB, and most took pride in helping combat the TB epidemic. But what struck participants most of all was how friendly, open and welcoming the research environment was in comparison to the public clinics and their other interactions with the state:

A lot of people don't treat you well. But like I've noticed here, they help you 
here. If you don't understand something they will explain it to you...Here they are friendly." (32, Female, Afrikaans)

The novelties of the trial can be attributed to a number of factors. This includes the highresource setting, the personalized attention, the strong retention motive, and the fact that clear communication and autonomous, voluntary decision-making are integral to the trials' ethical protocols (Geissler et al. 2008; Sariola \& Simpson 2011). The effect was that, in contrast to many other places in their social and material environment where they felt vulnerable and exposed, at SATVI participants felt valued, needed, and respected. As Stadler and colleagues (2016:507) argue, the trials became a "symbol of hope," offering positive imaginative horizons beyond the violence and instabilities of the everyday. But in order to demonstrate how the trials took on moral force, we turn to a deeper exploration of the relationships and interactions attendant upon the production of knowledge.

\section{"LOOKING” BEYOND WHAT YOU "SEE”}

It was not easy for all SATVI's research staff to make the transition from healthcare to research. While research was attractive for a number of reasons (e.g. good pay and hours), they were all trained to care for people. Several had worked in the government system and were thus accustomed to having greater command over patients than they did in the "flatter" staffparticipant relations of the research environment. At the same time, the rhythms of trial protocols generated novel possibilities for staff to engage with people who they knew - often very personally - to experience numerous social challenges. While the trial protocols were oriented towards the production of "objective" bioscientific knowledge, research relationships were porous to a broad spectrum of roles, imperatives, and subject positions from which participants and staff approached and made meaning of the trials. This is shown no better than in the interactions between Susanna and Leighton. 
In Worcester, as in other towns in the Western Cape, religion features prominently in the organization of social life. Evidence of the centrality of religion is the twenty-plus churches in the town, as well as a smaller number of mosques and other religious institutions. Susanna, one of the more privileged members of her religious community, explained that in her work with the church, it was an everyday occurrence that people came through the doors looking for spiritual guidance, often deeply unhappy with their lives and circumstances. A large part of her life beyond SATVI involved counselling people, explaining to them that they were valuable in the eyes of God and, more generally, trying to instill in them a hope for better. Through this church work, she was well-known in Worcester: "I know a lot of them, and they know me ...When they go home, and I pass them, they say, isn't that the pastor's wife?" She went on to explain that she found it impossible to vacate her role as church leader when coming to work at SATVI every morning:

For me it blends in. The church, and my work, it blends in ... Everyone who comes in here - I don't know if it's because my husband is a preacher - but I see them as someone valuable. That's how I see them. If they come in here, I will never see you as a participant, you're valuable to me. So, for me I'll never ever see you as an object [sic]. I'll see you as, you have a soul.

The close historical relationship between Christianity and biomedicine in South Africa, and the missionary origins of the medical profession, have been well-documented by social scientists (Vaughan 1991; Marks 1994; Hull 2009). Here, Susanna's remarks can be seen as a way of expressing through a Christian lens a tension that often emerges in the context of medical research. This is the tension between the abstract, distanced logic of trial protocols - where participants are objects of experimentation - and the needs, expectations, and subjectivities of those with whom frontline research staff interact (Easter et al. 2006; Fisher 2009; Sariola and 
Simpson 2011). For Susanna, participants were not valuable simply as a means to an end, where the only reason for being "nice" to them was to convince them to return time and again for the purposes of the trial. Rather, participants had inherent value as created beings with a purpose that vastly transcended the category of "participant." She felt it important that this was recognized, not only by her but among all her colleagues: "I normally watch that the other staff also treat the participants the correct way; I'm very strict about that. They're a participant, but please look at them beyond what you see."

Susanna's way of "looking" at participants also compelled her to engage with and intervene in the lives of participants. This was made possible partially by the greater time that research staff were able to spend with each person, in comparison to the public clinics; hence relationships could develop over weeks, months, and even years. Susanna used her time with participants to counsel them at length:

I will sit, I will do what I must do, then if there's time - I know it's busy - I will counsel them, have long discussions with them. But I know who you are, and I will treat you like that. So, if you go, I'm sure that you will come back again. For that reason [read: not for the money]. And you will tell the others outside...And the next time, when they come in here, you can see there's a difference, there's a change. Because they won't come in here like, dirty again. They will try to be better. Really, you can observe that.

As well as being central to the organization of social life, religion has, from Victorian times, been a key site in which Coloured elites attempted to "improve" the moral subjectivities of the poor, particularly regarding alcohol abuse: "the most visible and humiliating indicator of their community's poverty and degradation" (Lewis 1987:14; see also Jensen 2008). Most churches heavily contested alcoholism, smoking and other forms of substance abuse, and insisted on a 
variety of bodily disciplines that ranged from lifestyle to appearances (Jensen 2008:181). Susanna, who like other research staff believed that most people took part in the trial for the money (often to buy alcohol and drugs), extended this logic of personal "improvement" through the everyday routines of the trials. Her use of the term "dirty" is especially evocative, referencing more than just poverty but also a lack of respectability, care for appearances, outlook, and lifestyle (Jensen 2008; Ross 2010). Moreover, as Kate Abney (2011) showed in a study of TB stigma in Khayelitsha, Cape Town, "dirt" and "dirty lifestyles" are closely symbolically associated with TB, contributing to the stigmatization of the disease. This association was alluded to by Susanna in her comparison between Leighton and her brother, who died of TB as a result of "his lifestyle ... It was so painful for our whole family, but I know he [Leighton] can do better." Yet Susanna also believed that, by interacting with them, she could have an effect upon them such that they would return to SATVI, not for the money but for the betterment of self and others. As she said, “they won't come in here like, dirty again. They will try to be better. Really, you can observe that." Thus, at the level of trial protocols, people were being shaped into quantifiable, commensurable objects of bioscientific knowledge. But in the same moment, on the ground it was the embodied moral agent that became the all-important object of knowledge and intervention.

This sharp resistance to practices considered to be "immoral" or "dirty" went beyond the requirements of trial protocols. Excessive consumption of alcohol and drugs was, on the whole, guarded against. But it was not for immunological reasons that these substances were frowned upon. Rather, it made for unreliable participants: they were (in theory) less likely to attend follow-up visits. But as long as a participant appeared reliable, trial protocols could quietly accommodate - and could do little about - such substances. 
When describing her interactions with Leighton, Susanna only made passing reference to the drawing and testing of blood. Explaining why she could not screen him while he was drunk, she remarked, "otherwise our blood results and things, they will be whack." But for Leighton, this practice held considerable significance. He resolved to quit smoking and drinking because, as he said, "those things go into my blood." Leighton's interpretations of the trial resonate strongly with how many other participants - and some research staff - made sense of SATVI's trials and the role of participants therein. Thus, before exploring Leighton's conversion in more detail, we explore the significance and symbolic richness of blood draws as a site of meaning-making.

Vaccines are SATVI's raison d'être. Yet for participants, vaccines made a fairly limited appearance: they were administered at the beginning of the trials and never again. Some people would not even pass screening and receive a vaccine. Blood draws, by contrast, were a far more visible presence during the trials. Everyone who visited the site had their blood drawn at least once and, should they pass screening and be enrolled, their blood was drawn at intervals through to the end-of-study visit often several years later. The most common way in which participation was explained was in terms of donations of blood (see also Geissler 2005; Fairhead, Leach, and Small 2006; Geissler et al. 2008; Kelly 2011). Participants' understandings of what was happening to their blood varied considerably. But given SATVI's associations with TB, most made reference to the disease in their narratives. Some suggested that research was being performed on their blood to find a cure for TB. Others followed a similar logic to blood transfusion. As one participant explained:

When I look around me and see the people in my community getting sick with $\mathrm{TB}$, that was my reason, there are many people who are suffering and who have $\mathrm{TB}$, so what is it to me, who is one of the healthy ones, just to help by donating [blood] (33, Male, Afrikaans). 
Insofar as the ethical guidelines that govern clinical trials are concerned, such interpretations of the trials testify to widespread "misconceptions" among SATVI's participants. However, we contend that people's emphasis on blood should not be delegitimized as a mere "misconception," but rather viewed as a conceptual solution to the abstract bioscientific understanding of how individual participation translates into public good (see also Fairhead et al. 2006; Geissler et al. 2008). Whereas the concept of a clinical trial is abstract and distanced, blood was something people knew. It was something that they found relatable and had experience with, for instance in healthcare settings, in the work of the blood transfusion service, and in religion (explored below). Blood provided a hermeneutic "point of entry" into the science; it allowed people to pull things in and make sense of the trials in a way that was familiar to them. Those who described the trials in terms of vaccines tended to do so with much hesitancy. The greater number of those who spoke the language of blood donation, by contrast, usually did so confidently and with considerable clarity.

What is significant about blood donation, however, is not only its destination but also what it revealed about those from whom blood was drawn. Several participants explained that blood had to be screened and confirmed to be disease-free before it could be circulated: "Me, blood that is taken...for sure is checked that it is right, and then it will support those people who need" (20, Female, Xhosa). But one phrase that began to emerge in participants' explanations was that the quality of blood needed by SATVI was "clean blood" (30, Male, Afrikaans). Perhaps the most illuminating example appeared not during the interviews but rather during an anthropology student field trip that we supervised. ${ }^{4}$ One student spoke to a mother of three, all four of whom were enrolled in trials at the time:

She and all three her children were involved in the program. I asked her to explain what SATVI did. She explained that they "take your blood," it's a kind of "donation" of blood. She didn't know what exactly they do with the blood, 
but she knew the blood had to be clean blood. So, if you are involved with SATVI you know you are healthy. She also went on to explain that they were particularly interested in getting school children's blood because it was "clean" (Field Report, T. Koster).

The remark about children's blood being clean is particularly revealing, suggesting both that their blood is disease-free, and conjuring images of purity, innocence and being untainted by the "dirty" practices usually associated with adulthood, such as drinking, smoking, and drugs (Douglas 1966; Abney 2011). The undesirability of such practices may have been influenced by the research staff. Susanna, for example, told Leighton that the alcohol he had drunk would be reflected in the blood work. Peter, one of the fieldworkers, explained:

And when I speak to the participants and parents and all this, I'm actually also telling them that, don't use drugs. Don't do that, because we as SATVI and the research we don't want you to do that because we need your blood, well you as a person, so don't do that.

The blood draws that lay at the heart of participation therefore not only revealed diseases and biological states. Blood also, in the same moment, acted as a window into lifestyle and a signifier of morality. Like the Malay politician explored by Carsten (2013b), and the women in the HIV trial explored by Stadler and colleagues (2016), SATVI was perceived to have the capacity to see the truth about people's moral agency through drawing and testing blood. SATVI's trials thus appear to operate a process of medical and moral triage, with only the "clean" able to enter and continue donating blood. Through the idiom of clean blood, the distinction between scientific object and moral subject collapsed. But how was triage experienced and performed in participants' day-to-day lives? 


\section{TRUTH AND THE EMBODIMENT OF “CLEAN BLOOD”}

Having explored the associations between SATVI and "clean blood," in this final section we revisit Leighton's experiences and conversion. While taking place in the midst of a bioscientific experiment, Leighton's conversion has parallels with Jensen's (2008) work with young Coloured men in Cape Town. Working in a township called Heideveld, Jensen focused upon the challenges of living in gang territories. Several of the young men he interacted with had either left or attempted to leave gang life, but this was incredibly difficult. Simply claiming to have departed gang life was not nearly enough: one had to demonstrate to both gangsters and "polite society" alike that one had truly left. Jensen shows that, just as religion was used by the Coloured elite to condition the bodies of the poor, it was also embraced by young men as an "embodied strategy of self-improvement" to leave their gangs (2008:181). Jensen spoke to a young man called Shaun who, in addition to apologizing to those he had wronged, described the embodied practices that he had had to perform to build trust:

If you are a Christian and carry a bible, then you can get out, but not by yourself.

You must be a Christian in their eyes. You mustn't smoke. You mustn't drink. Walk with a suit and your bible, and they will see that you are a Christian. That is why they won't touch you. $(2008: 182)$

All the while, however, the "dual consciousness" of Colouredness remained, always threatening to undermine Shaun's efforts at rehabilitation. As Jensen puts this, people were "watching his every move for traces of what was presumably was always already there ... the paradox that faced all coloured men from the townships as they staked their claims to respectability" (2008:183). We contend that Leighton, like Shaun, used religion as an "embodied strategy of self-improvement" (see also Black 2015). However, Leighton's strategy takes on additional moral significance because Susanna's Christian message was refracted through and amplified 
by the idiom of clean blood.

On first glance, it might seem unintuitive that the routine medical practice of drawing and testing blood during clinical trials might find affinity with a conversion to Christianity. However, Carsten (2013a) supports her characterization of blood as the "stuff of truth," by drawing attention to a long history of this conceptualization of blood in Christian thought. In the same volume as Carsten, Bildhauer (2013) finds in Medieval texts the reoccurring notion that blood that is rendered visible has the ability to reveal people's innermost states, including truths about both their health and their moral propriety. Carsten (2013a:S8) adds that these ideas are themselves partially derived from biblical writings, for instance Leviticus (17:1-15), which depicts blood as "both the animating life force and the bearer of the soul." SATVI's blood draws - which, for many participants constituted the "beating heart of the trials" (Brives 2013:397) might thus be read as an act of making blood visible, revealing both biological and moral truths, while also an underlying conceptual synergy between Christianity and blood draws.

Susanna, as observed above, was committed to "looking" beyond what she "saw." But from where Leighton was sitting, this was aided by the drawing and testing of blood, offering a particularly powerful means of looking and knowing. SATVI would, in effect, know exactly what he had been doing in and between his visits to the site, whether or not he told them. SATVI's knowledge and visibility had profound effects upon Leighton's outlook and lifestyle, as he explained:

I never knew how healthy I was. Even now when I'm out there in the community, I know my status. I know I'm a hundred percent. Nothing is wrong with me...I don't have fear when I'm walking there because I know I'm healthy. Because now I'm over the weekend. A lot of things are happening on a weekend. People are drinking beer, partying and all those things. Because I know I'm a part of SATVI, I don't belong in those things. 
Because he was a part of SATVI, he suggests, he could no longer take part in some of the things that he did before, particularly "drinking beer, partying and all those things." For Leighton, following protocol - conceived of as not partaking in "dirty" practices - was akin to following the word of God. Hence in the opening vignette, he said: "I want to be in this study also to stop these things. Because if I keep on doing that, I'm with God." It is as though a church preacher had the remit to draw and test blood as an act of religious confession. That is what was happening when Leighton came for follow-up visits - an extension and amplification of religious authority through the protocols of bioscientific experimentation.

Leighton's case shows how trial participation might constitute a powerful strategy of self-improvement: one had to embody and perform what it meant to be someone of "clean blood" to continue to participate in the trial (Black 2015). As observed earlier, the significance of clinical trials for people living in poverty has usually been thought of in terms of offering material benefits, especially healthcare and money. However, when we broaden our horizons to the multiple roles, imperatives and subject positions from which people approach and make meaning of clinical trials, we can see other forms of "benefit" emerging from participation. From Leighton's perspective, for instance, belonging to the trial conferred upon him a powerful form of symbolic capital. It was something he could wear on his sleeve - much like a suit and a bible - to demonstrate that he did not belong in certain kinds of practices anymore and that he was helping rid the community of TB by doing so. Post-apartheid Worcester is a context that strips away possibilities for self-worth, not only because of a lack of opportunity but also the stereotypes with which people must contend. Given the suspicion of principles like "autonomy" and "volunteerism" in critiques of medical neoliberalism and bioethics, it is easy to overlook what it might mean to feel valued, needed, and capable of making moral decisions for oneself and for others.

Whilst participation might constitute a powerful strategy of self-improvement, it is 
important not to lose sight of the fragility of positive lifestyle changes in a destabilized and impoverished urban environment. We were largely unable to talk to people who were excluded from the trials (discussed above). But we did receive hints that some people felt unable to return to SATVI in the wake of "deviations" from the lifestyle they felt was required. Leighton, for instance, said that he knew people who had not "made it" through triage: "They are not making it because every time you are here, you are being tested, so it tells you about what we are doing in past days since the last time that you were meeting." In addition, some of the students during the aforementioned anthropology field trip encountered a man who said that "dirty blood" was the reason he left a trial:

\begin{abstract}
"SATVI used my blood. But now, my blood is dirty; I partake in other things that cause my blood to not be clean anymore." Tylor asked him if he could tell us what these 'things' were that caused his blood to not be clean anymore, and he just smiled and stated: "Simply just things." We both could see that he did not want to elaborate on the situation (Field Report, K. Opperman).
\end{abstract}

Insofar as trial protocol was concerned, he would not have been excluded because the quality of his blood had been compromised by drinking or drugs. It is, in fact, possible that he was not formally excluded at all, but simply felt too ashamed to return, which was perhaps suggested by his response. But even if he was excluded from the trial - perhaps because he had developed TB or another medical condition - the way he understood exclusion was not in the amoral, matter-of-fact way of a trial protocol. Rather, it was perceived as a personal moral failing. This emphasizes that the moral triage enacted by the trials might have been empowering and uplifting for some, but a source and dejection and shame for others. 


\section{CONCLUSIONS}

We have highlighted the possibilities generated by trial participation for participants to demonstrate healthiness, respectability and godliness in an impoverished past-apartheid setting. The positive uptake of SATVI's trials among participants, we suggested, was informed by the long history of racialized exclusion, domination, and stereotyping in South Africa that has endured into the post-apartheid era and that intersects with discourses of "irresponsibility" in the health sector (e.g. Montgomery 2012; Stadler et al. 2016). People's interpretations of the trials crystallized around the notion of "clean blood," an emergent idiom that collapses the distinction between scientific object and moral subject and between personal and community health. Trial participation conferred a status and a responsibility upon participants that, for some like Leighton, could be highly empowering, a powerful and performative "strategy of selfimprovement" (Jensen 2008:181; see also Black 2015). Yet, the demands of the trials were for others unsustainable in the harsh urban climate of post-apartheid Worcester. We used the notion of "moral triage" to capture the high stakes involved and the moral force taken on by the trials beyond the requirements of trial protocols.

As we began to notice these subtle movements and transformations during fieldwork, we realized that they fell in the blind spot between two competing discourses about trial participation. They neither mapped neatly onto the abstract, a-relational imaginings of "global" science and ethics, nor conformed to the pervasive local discursive attributing SATVI's high recruitment rates to the R150 "reimbursements." Social science critiques tend to portray the latter as being closer to the reality of trials in contexts of extreme inequality. Yet as we showed, ascriptions of material intent were highly problematic and historically loaded, with people selfconsciously (re)framing and performing their intentions in terms of the betterment of self and society. We might view trial participation in this setting as a form of situated, performative volunteerism - continuously re-enacted and never stable, but indicative of a different dimension 
of what participation might mean on the peripheries of social and economic life beyond material benefit. On one level, we have thereby shown just how deeply clinical trials permeate social and cultural life, revealing and reconfiguring the very substance of moral personhood. On another, however, we have tried to capture the diverse and unpredictable ends to which trials are put, confounding assumptions about how people will respond when trials "come to town." Just as clinical trials are oriented towards a particular (biomedicalized) vision of the future, so too participants' own hopes for better are refracted though everyday scientific practices and routines, inadvertently transforming the bodies that the technologies of "global" science purport to represent.

\section{Funding}

This study was funded by a Collaborative PhD Studentship from the Economic and Social Research Council, United Kingdom [000263500].

\section{Acknowledgements}

We would like to thank all of the clinical trial participants, researchers and public clinic staff who were a part of this study. We also thank three anonymous reviewers for their insightful comments. This study received ethical approval from the University of Cape Town's Human Research Ethics Committee.

\section{References}

Abadie, R.

2008 The Professional Guinea Pig: Big Pharma and the Risky World of Human Subjects. Durham, NC and London: Duke University Press.

Abney, K. 
2011 Whoever Said a Little "Dirt" Doesn't Hurt? Exploring Tuberculosis (TB)-Related Stigma in Khayelitsha, Cape Town. MA Dissertation, Department of Social Anthropology, University of Cape Town.

Abrams, A., N. Siegfried, and H. Geldenhuys

2011 Adolescent experiences in a vaccine trial: A pilot study. South African Medical Journal 101(12):884-86.

Andanda, $\mathrm{P}$.

2005 Module two: Informed consent. Developing World Bioethics 5(1).

Barsdorf, N., S. Maman, N. Kass, and C. Slack

2010 Access to treatment in HIV prevention trials: Perspectives from a South African community. Developing World Bioethics 10(2):78-87.

Bildhauer, B.

2013 Medieval European conceptions of blood: Truth and human integrity. Journal of the Royal Anthropological Institute 19(S1):S57-76.

Black, S. P.

2015 The morality of performance: HIV disclosure in speech and song in South Africa. Ethos 43(3):247-66.

Brives, C.

2013 Identifying ontologies in a clinical trial. Social Studies of Science 43(3):397-416.

2016 Biomedical packages: Adjusting drug, bodies, and environment in a phase III clinical trial. Medicine Anthropology Theory 3(1):1-28.

Carsten, J.

2013a Introduction: Blood Will out. Journal of the Royal Anthropological Institute 19(S1):S1-23. 
2013b "Searching for the Truth": Tracing the Moral Properties of Blood in Malaysian Clinical Pathology Labs. Journal of the Royal Anthropological Institute 19(S1):S130-48. Compion, S.

2008 Tuberculosis Discourse in South Africa: Knowledge, Power and Ideology.

Saarbrucken, Germany: VDM Verlag Dr Muller Aktiengesellschaft \& Co. KG.

Douglas, M.

1966 Purity and Danger. London: Routledge and Kegan Paul.

Easter, M. M., G. E. Henderson, A. M. Davis, L. R. Churchill, and N. M. P. King 2006 The many meanings of care in clinical research. Sociology of Health \& Illness 28(6):695-712.

Fairhead, J., M. Leach, and M. Small

2006 Where techno-science meets poverty: Medical research and the economy of blood in The Gambia, West Africa. Social Science \& Medicine 63:1109-20.

Farmer, P.

1998 Editorial: Nihilism and pragmatism in tuberculosis control. American Journal of Public Health 88(7):1014-1015.

2000 The consumption of the poor: Tuberculosis in the 21st century. Ethnography 1(2):183-216.

Fisher, J.

2009 Medical Research for Hire: The Political Economy of Pharmaceutical Clinical Trials. New Brunswick, NJ: Rutgers University Press.

Geissler, P. W.

2005 “Kachinja are coming!” Encounters around medical research work in a Kenyan village. Africa 75(2):173-202. 
2011 “Transport to where?" Reflections on the problem of value and time á propos an awkward practice in medical research. Journal of Cultural Economy 4(1):45-64.

2013 Public secrets in public health: Knowing not to know while making scientific knowledge. American Ethnologist 40(1):13-34.

Geissler, P. W., A. H. Kelly, B. Imoukhuede, and R. Pool 2008 "He is now like a brother, I can even give him some blood" Relational ethics and material exchanges in a malaria vaccine 'trial community' in The Gambia. Social Science \& Medicine 67:696-707.

Harper, I.

2006 Anthropology, DOTS and understanding tuberculosis control In Nepal. Journal of Biosocial Science 38(1):57-67.

Hull, E. A.

2009 Status, Morality and the Politics of Transformation: An Ethnographic Account of Nurses in KwaZulu-Natal, South Africa. PhD Dissertation, Department of Anthropology, London School of Economics and Political Science.

Jensen, $\mathrm{S}$.

2008 Gangs, Politics and Dignity in Cape Town. Oxford, UK: James Currey.

Jewkes, R., N. Abrahams, and Z. Mvo

1998 Why do nurses abuse patients? Reflections from South African obstetric services. Social Science and Medicine 47(11):1781-95.

Joyner, K., T. Shefer, and E. Smit

2014 Discourses and practices in institutionalised nursing in South Africa: Challenges for care. South African Review of Sociology 45(3):34-52. 
Kamuya, D. M., V. M. Marsh, P. Njuguna, P. Munywoki, M. Parker, and S. Molyneux 2014 "When They See Us, It's like They Have Seen the Benefits!": Experiences of study benefits negotiations in community-based studies on the Kenyan Coast. BMC Medical Ethics 15(1):90.

Kelly, A. H.

2011 Remember Bambali: Evidence, Ethics and the Co-Production of Truth. In Evidence, Ethos and Experiment: The Anthropology and History of Medical Research in Africa. P. W. Geissler, ed. Pp. 229-44. New York: Berghahn Books.

Kingori, $\mathrm{P}$.

2013 Experiencing everyday ethics in context: Frontline data collectors' perspectives and practices of bioethics. Social Science and Medicine 98:361-70.

2015 The "empty choice": A sociological examination of choosing medical research participation in resource-limited Sub-Saharan Africa. Current Sociology 63(5):763-78.

Lewis, G.

1987 Between the Wire and the Wall: A History of South African 'Coloured' Politics. Cape Town: David Phillip.

Marks, S.

1994 Divided Sisterhood: Race, Class and Gender in the South African Nursing Profession. Johannesburg: Witwatersrand University Press.

Molyneux, S., D. Kamuya, P. A. Madiega, T. Chantler, V. Angwenyi, and P. W. Geissler. 2013 Field workers at the interface. Developing World Bioethics 13(1):ii-iv.

Montgomery, C.

2012 Making prevention public: The co-production of gender and technology in HIV prevention research. Social Studies of Science 42(6):922-44. 
Nguyen, V.-K.

2005 Antiretroviral Globalism, Biopolitics, and Therapeutic Citizenship. In Global Assemblages: Technology, Politics, and Ethics as Anthropological Problems. A. Ong, ed. Pp. 124-44. London: Blackwell.

2015 Treating to Prevent HIV: Population Trials and Experimental Societies. In ParaStates and Medical Science: Making African Global Health. P. W. Geissler, ed. Pp. 4777. Durham, NC: Duke University Press.

2010 The Republic of Therapy: Triage and Sovereignty in West Africa's Time of AIDS. Durham, NC: Duke University Press.

O’Donnell, M. R., N. Padayatchi, C. Kvasnovsky, L. Werner, I. Master, and C. R. Horsburgh. 2013 Treatment outcomes for extensively drug-resistant tuberculosis and HIV coinfection. Emerging Infectious Diseases 19(3):416-24.

Petryna, A.

2009 When Experiments Travel: Clinical Trials and the Global Search for Human Subjects. Princeton, NJ: Princeton University Press.

Robins, S.

2006 From "rights" to "ritual": AIDS activism in South Africa. American Anthropologist 108 (2): 312-23.

Ross, F. C.

2010 Raw Life, New Hope: Decency, Housing and Everyday Life in a Post-Apartheid Community. Cape Town: University of Cape Town Press.

Rottenburg, R.

2009 Social and public experiments and new figurations of science and politics in 
postcolonial Africa. Postcolonial Studies 12(4):423-40.

Salo, E..

2003 Negotiating gender and personhood in the new South Africa: Adolescent women and gangsters in Manenberg township on the Cape Flats. European Journal of Culturul Studies 6(3):345-65.

Sariola, S. and B. Simpson

2011 Theorising the "human subject" in biomedical research: International clinical trials and bioethics discourses in contemporary Sri Lanka. Social Science \& Medicine 73(4):515-21.

Simpson, B., R. Khatri, D. Ravindran, and T. Udalagama

2015 Pharmaceuticalisation and ethical review in South Asia: Issues of scope and authority for practitioners and policy makers. Social Science \& Medicine 131:247-254.

Stadler, J., F. Scorgie, A. van der Straten, and E. Saethre

2016 Adherence and the lie in a HIV prevention clinical trial. Medical Anthropology 35(6):503-16.

Sunder Rajan, K.

2005 Subjects of speculation: Emergent life sciences and market logics in the United States and India. American Anthropologist 107(1):19-30.

2017 Pharmocracy: Value, Politics, and Knowledge in Global Biomedicine. Durham, NC and London: Duke University Press.

Vaughan, M.

1991 Curing Their Ills: Colonial Power and African Illness. Stanford, CA: Stanford University Press.

Walker, L. and L. Gilson 
2004 "We are bitter but we are satisfied": Nurses as street-level bureaucrats in South Africa." Social Science \& Medicine 59(6):1251-61.

Wendland, C. L.

2008 Research, therapy, and bioethical hegemony: The controversy over perinatal AZT trials in Africa. African Studies Review 51(3):1-23.

White, L.

2000 Speaking with Vampires: Rumor and History in Colonial Africa. Berkeley, CA: University of California Press.

World Health Organisation

2016. Global Tuberculosis Report.

http://apps.who.int/iris/bitstream/10665/250441/1/9789241565394-eng.pdf?ua=1

Zigon, J.

2008 Morality: An Anthropological Perspective. Oxford, UK: Berg.

\section{Notes}

\footnotetext{
${ }^{1}$ All personal names are pseudonyms.

${ }^{2}$ Approximately $£ 8$ at the time of writing.

${ }^{3}$ Participants quite often expressed more than one reason for taking part.

${ }^{4}$ This trip was part of an anthropology methods course at the University of Cape Town, in which students asked local residents about SATVI's work. We use two quotes from the students' field reports, for which permissions have been obtained.
} 